\title{
Entendendo o desempenho no futebol: relato de uma atividade no Ensino Médio
}

\section{Thiago Brañas de Melo}

Professor, IFRJ / Campus São Gonçalo

thiago.branas@ifrj.edu.br

\begin{abstract}
Resumo
A experiência relatada teve como objetivo instigar a prática de coleta, organização e análise de dados através da disciplina de Matemática. A turma foi uma do primeiro ano do Ensino Médio de um Instituto Federal da região metropolitana do Rio de Janeiro. O tema da atividade, escolhido pelos alunos, foi o futebol. Eles criaram gráficos que representavam o desempenho de alguns times do Campeonato Brasileiro de Futebol 2011 e buscaram, em sites de notícias, fatos que o justificasse. Com a experiência, verificou-se que este tipo de atividade possibilita uma formação mais reflexiva.
\end{abstract}

Palavras-chave: Atividade de Coleta, Organização e Análise de Dados; Educação Matemática; Ensino Médio; Futebol.

\section{Understanding the performance in soccer: report of an activity in High School}

\begin{abstract}
The experience being reported aims at motivating to do data collection, organization and analysis into mathematics. We have chosen a class of first year high school students of the Federal Institute in the metropolitan region of Rio de Janeiro. The theme of the activity, which was chosen by the students, is about soccer. They have devised graphs which represent the performance of some teams of the 2011 Brazilian Soccer Championship, and they have searched on Internet sites for some facts which could justify the performance. We have observed that this kind of activity implies in a more reflexive training.
\end{abstract}

Keywords: Data Collection, Organization and Analysis Activity; Mathematical Education; High School; Soccer. 


\section{Reflexões introdutórias}

Ao ler o livro "Educação e Alfabetização Científica" de Pedro Demo (2010), surgiu uma indagação: será que eu possibilito a educação e a alfabetização científica dos meus alunos? Segundo o autor, quando o docente apenas transmite, de forma automática, usando apenas materiais prontos (como o livro didático), não dá oportunidade de o aluno ganhar maturidade e se emancipar quanto à produção de conhecimento. Ele argumenta que os alunos desde pequenos aprendam a pensar e ter rigor em suas práticas, isso significa saber recolher dados, trabalhar os dados e chegar a conclusões próprias apoiadas por uma teoria. Obviamente adequando as atividades à idade dos discentes.

Para Demo (2010), existem quatro condições para que a educação científica tenha o devido impacto estrutural almejado na sociedade atual, são elas: reconstruir outras estratégias de aprendizagem, refazer a proposta de formação docente, transformar a escola em laboratório de pesquisa e produção de conhecimento, e transformar os alunos em pesquisadores. $\mathrm{O}$ autor acredita que esta última condição deva ser exercida desde a tenra idade, adequando os trabalhos às faixas etárias. Já na educação básica, pode-se incentivar uma leitura crítica de dados e uma escrita rigorosa de análise e conclusões.

A leitura deste livro me fez recordar da Educação Matemática Crítica de Ole Skovsmose, em especial, seu artigo "Cenários para Investigação" (SKOVSMOSE, 2008) e o livro em parceria com Helle Alrø (ALRØ e SKOVSMOSE, 2006). Os dois textos fazem uma reflexão sobre um ambiente educacional aberto ao diálogo, onde questionar é fugir de um contrato implícito entre professor e aluno que regulamenta a permanente soberania do saber docente.

Um cenário para investigação possibilita professor e aluno, diante de um problema, fazerem as seguintes perguntas: "O que acontece se...?" ou "Por que isto? ”. Skovsmose (2008) cita diversas situações possíveis para se criar um cenário para investigação, não importando se este faz referência a problemas da matemática pura, da semi-realidade ou da realidade. Ele ainda aponta que para um professor construir um cenário para investigação, ele deve sair da zona de conforto, onde a matemática e, consequentemente, suas falas, são inquestionáveis, para uma zona de risco, onde as atividades didáticas carecem de constantes reorganizações devido às indagações surgidas no meio do processo.

O diálogo é um dos pontos chaves para se criar um cenário para investigação, segundo Alrø e Skovsmose (2006). Para os autores, o processo de aprendizagem dialógico, além de possibilitar a investigação e situar o professor na zona de risco, é a base para promoção da igualdade. No intuito de posicionar mais suas ideias, eles caracterizam o diálogo "como um processo envolvendo atos de 
estabelecer contato, perceber, reconhecer, posicionar-se, pensar alto, reformular, desafiar e avaliar" (p. 135).

Feita uma leitura dos textos que me levaram a formular a atividade a ser relatada, descrevo como se deu o processo que teve como objetivo instigar nos alunos a prática de coleta, organização e análise de dados.

\section{A atividade}

A turma em que a atividade foi aplicada era composta por alunos do primeiro ano de um Curso Técnico Integrado ao Ensino Médio, de um Instituto Federal da região metropolitana do Rio de Janeiro. Importante frisar que currículo estipulado pela instituição à disciplina de matemática já define competências conteudistas baseadas em um ensino tradicional. E este currículo, considerado rígido por alguns professores da instituição, já alcança um aprofundamento matemático. Assim, a experiência relatada não buscou aprendizado de algum tema matemático específico. A atividade almejava a construção, por parte dos alunos, de uma visão mais externalista da matemática enquanto linguagem que traduz situações reais, além de possibilitar a iniciação dos alunos na prática de coleta, organização e análise de dados.

A turma em que a atividade foi desenvolvida tinha um total de 34 alunos, sendo 18 do sexo masculino e 16 do sexo feminino, com uma faixa etária média entre 15 e 16 anos. O primeiro passo da atividade foi definir o tema. Considero que o tema deva atender os interesses sociais e culturais dos alunos. Ele pode ser escolhido de duas formas: pelos alunos, de acordo com os seus gostos; ou pelo professor (ou pesquisador), quando os alunos não têm condições de conceber previamente a importância de algum tema. Optei pela primeira forma e levei um questionário com sugestões de temas (ver figura 1).

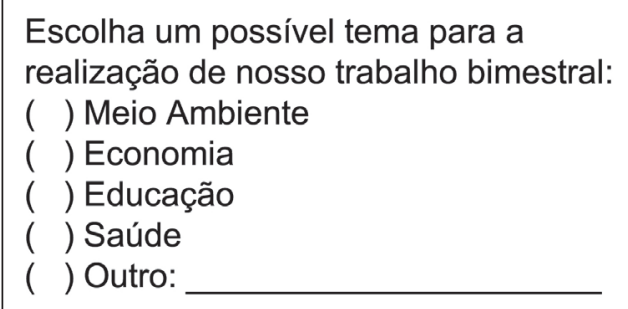

Figura 1 - Questionário sobre o tema

Na tabela 1, está listado o resultado da pesquisa respondida por 32 alunos da turma. Nota-se que além das opções originais, outras três foram enunciadas pelos 
alunos: futebol, RPG e construção civil. E o tema escolhido pela maioria, em especial, os alunos do sexo masculino, foi o futebol. A escolha não foi uma surpresa, pois o questionário foi aplicado na semana que antecedia a última rodada do Campeonato Brasileiro de Futebol, série A, do ano de 2011.

\begin{tabular}{ll}
\hline Tema & Quantidade de votos \\
\hline Meio Ambiente & 5 \\
\hline Economia & 2 \\
\hline Educação & 4 \\
\hline Saúde & 1 \\
\hline Futebol & 15 \\
\hline RPG & 4 \\
\hline Construção Civil & 1 \\
\hline Total & 32 \\
\hline
\end{tabular}

Tabela 1 - Resultado da aplicação do questionário sobre o tema

Após a escolha do tema, refleti sobre uma possível atividade cujo objetivo maior fosse desenvolver, ou construir, a capacidade de coletar, organizar e analisar dados. A proposta foi a seguinte: os alunos deveriam modelar por um gráfico o desempenho de um dos times no Brasileirão 2011, Série A do Campeonato Brasileiro de Futebol, e buscar notícias com fatos que justificassem este desempenho.

Para evitar conflitos e repetições a respeito de um time específico, a turma foi dividida em sete grupos, compostos por quatro ou cinco alunos. Cada grupo obteve duas ou três opções de times por meio de um sorteio. O grupo deveria escolher um dos times disponíveis. Na tabela 2 se encontra a divisão dos times entre os grupos.

\begin{tabular}{llll}
\hline Grupo & Quantidade de alunos & Possíveis times & Time escolhido \\
\hline 1 & 5 alunos & América-MG, América-GO, Atlético-MG & América-MG \\
\hline 2 & 5 alunos & Atlético-PR, Avaí, Bahia & Bahia \\
\hline 3 & 5 alunos & Botafogo, Ceará, Corinthians & Botafogo \\
\hline 4 & 5 alunos & Coritiba, Cruzeiro, Figueirense & Cruzeiro \\
\hline 5 & 5 alunos & Flamengo, Fluminense, Grêmio & Fluminense \\
\hline 6 & 4 alunos & Internacional, Palmeiras, Santos & Santos \\
\hline 7 & 5 alunos & São Paulo, Vasco & Vasco \\
\hline
\end{tabular}

Tabela 2 - Escolha dos times a serem analisados 
Os grupos modelaram o desempenho dos times por meio de um gráfico, como lhes foi pedido. Os gráficos representam a evolução da pontuação dos times no Brasileirão em relação ao número de rodadas. Eles podem ser visualizados nas figuras de 2 a 8.

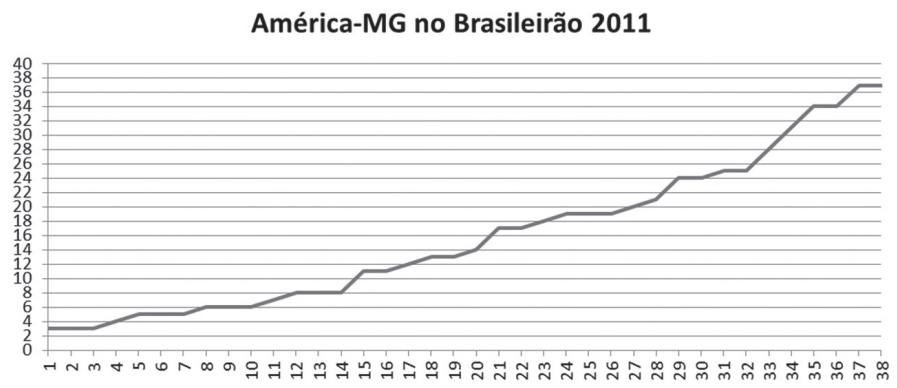

Figura 2 - Gráfico do grupo 1 (América-MG)

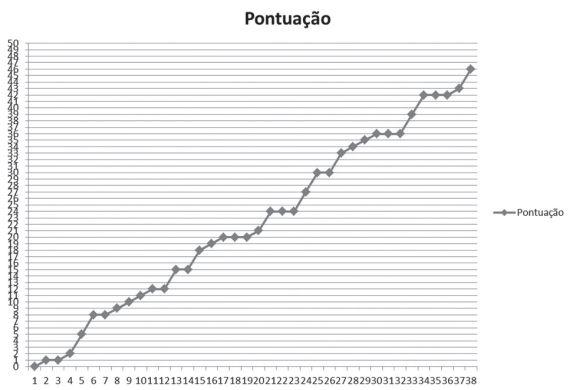

Figura 3 - Gráfico do grupo 2 (Bahia)

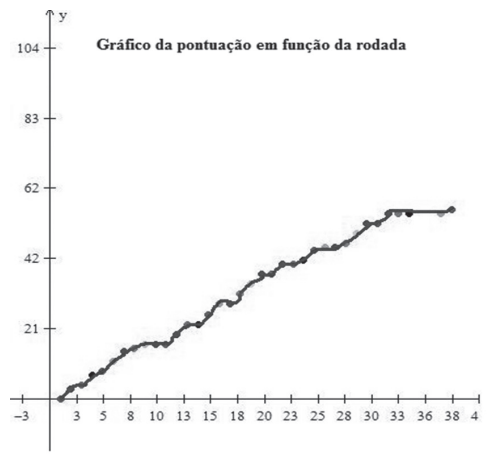

Figura 4 - Gráfico do grupo 3 (Botafogo) 


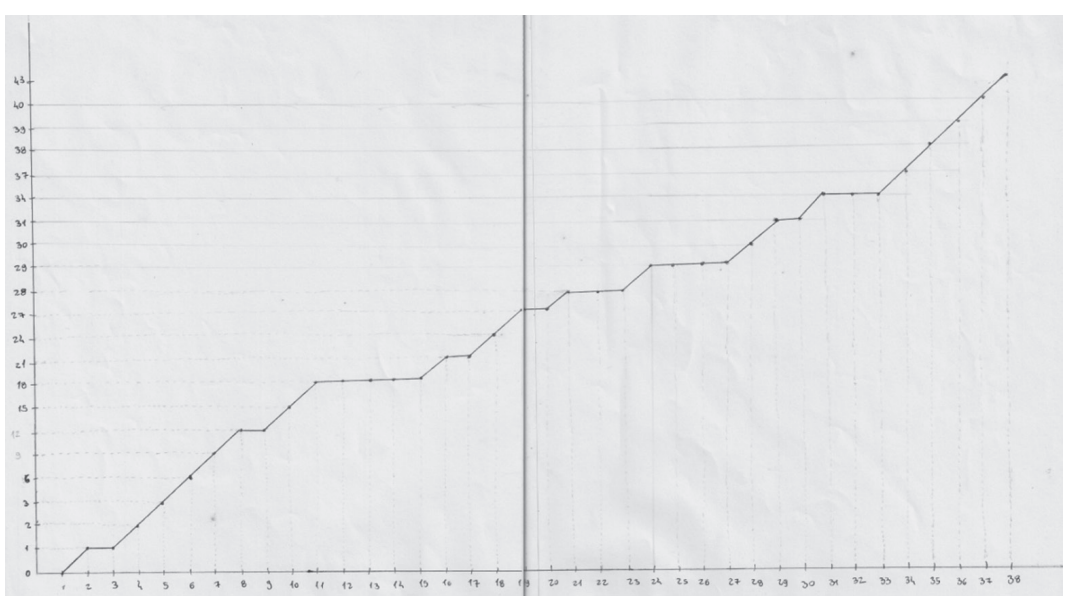

Figura 5 - Gráfico do grupo 4 (Cruzeiro)

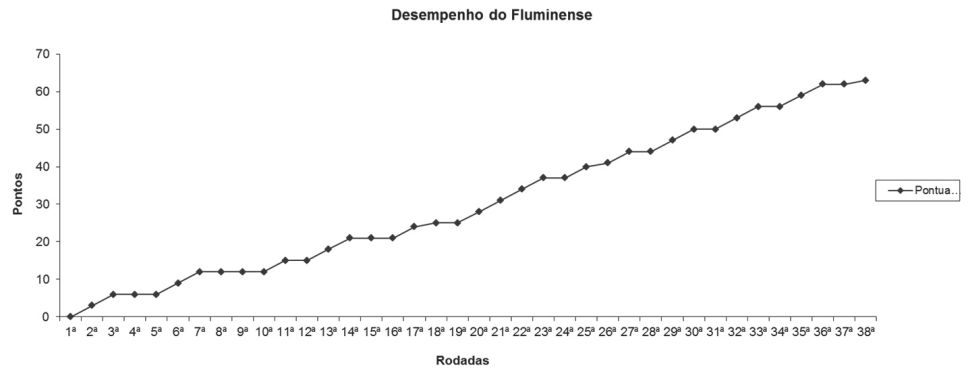

Figura 6 - Gráfico do grupo 5 (Fluminense)

Gráfico 1

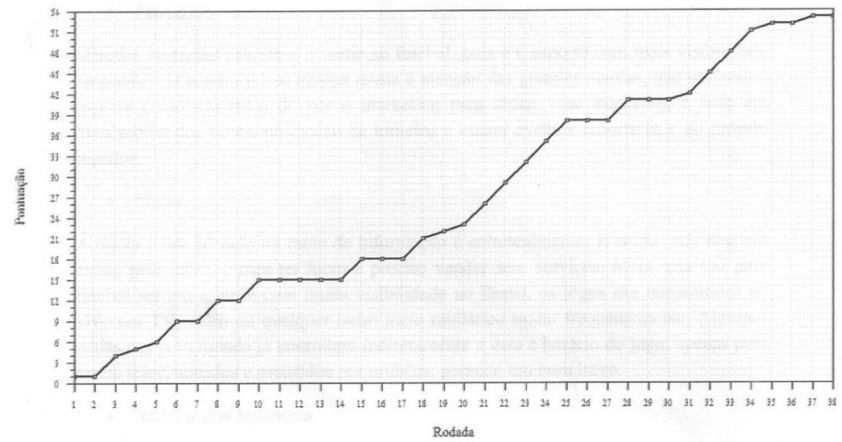

Figura 7 - Gráfico do grupo 6 (Santos) 


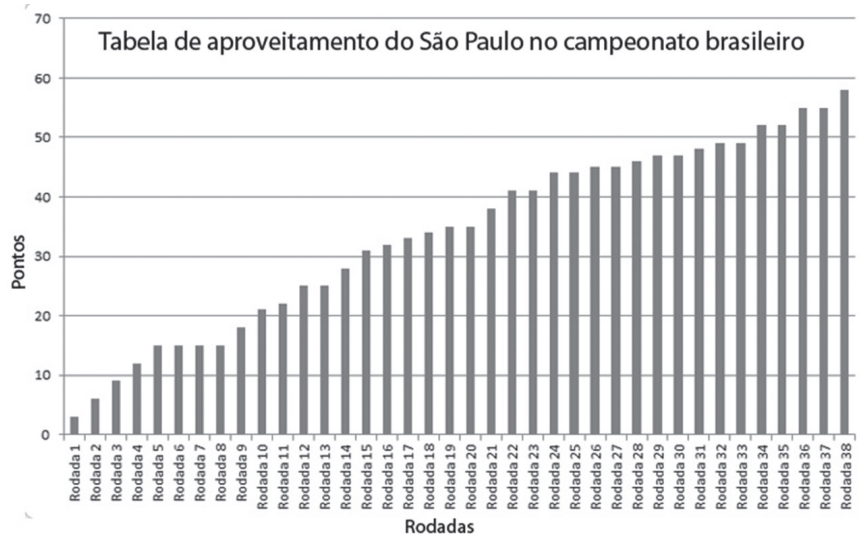

Figura 8 - Gráfico do grupo 7 (São Paulo)

Após os alunos modelarem os gráficos, eles analisaram cada crescimento ou estagnação da pontuação de acordo com eventos reais ocorridos em torno do time. As justificativas deveriam ser baseadas em reportagens veiculadas na imprensa. Cito alguns pontos em que os alunos se ativeram em seus trabalhos:

- O grupo 1 focou suas observações na atuação do América-MG frente aos times cariocas, já que a principal rede de comunicação do país tem um tendência a divulgar fatos ocorridos na cidade do Rio de Janeiro, sede da empresa.

- O grupo 2 apontou a alegria da torcida do Bahia pela ascensão do time de 2010 para 2011, da séria B para série A do campeonato, e a sua luta para aí permanecer, pois o time enfrentou problemas financeiros que acabaram interferindo no desempenho.

- O grupo 3 destacou fatores como contratações feitas durante o campeonato, convocação de um dos seus jogadores para seleção, reeleição da diretoria atual e instabilidade emocional dos jogadores como influenciadores nos resultados.

- O grupo 4 argumentou que durante todo o campeonato o time do Cruzeiro lutou para não ser rebaixado para a segunda divisão, o que acabou sendo um elemento motivador de vitórias nas últimas rodadas, possibilitando a permanência do time na Série A.

- O grupo 5 separou sua análise do time do Fluminense em influência positivas (alto número de gols do jogador Fred e troca do treinador do time) e influências negativas (grande número de derrotas jogando "em casa" e mau desempenho nos jogos considerados "clássicos"). 
- O grupo 6 chamou o time dos Santos de "o time com o luxo de não se preocupar com o título", pois já havia conquistado a vaga na Libertadores 2012 e ainda focou o bom desempenho na luta pelo título da Taça Libertadores 2011 e no Mundial de Clubes.

- O grupo 7 argumentou, anexando 39 weblinks de reportagens, que os principais fatos ocorridos no time do São Paulo, que se mostrou instável durante parte do campeonato, foram contusões e contratações de jogadores e troca de técnicos.

Após a partilha dos trabalhos dos grupos com toda a turma, eles se reuniram novamente no intuito de concluir a atividade, buscando responder a questão: quais os elementos mais influenciadores no desempenho dos times no Brasileirão 2011 ? As respostas podem ser vistas na tabela 3 .

\begin{tabular}{ll}
\hline Elementos & Grupos que citaram \\
\hline Saúde dos jogadores & $1,2,5$ \\
\hline Contratações e demissões de jogadores & $1,2,7$ \\
\hline Confrontos com times rivais (chamados “clássicos") & 1,5 \\
\hline Mídia (jornalismo, publicidade ou jornalismo/publicidade) & $1,3,4,6,7$ \\
\hline Comportamento (satisfação/fanatismo) da torcida; torcidas organizadas. & $1,2,3,6,7$ \\
\hline Patrocinadores & $2,3,6,7$ \\
\hline Infraestrutura (estádios e sede própria) & 2,4 \\
\hline Lazer & 3 \\
\hline Salários dos jogadores & $3,4,6$ \\
\hline Segurança durante as partidas & 4 \\
\hline Arbitragem & 4 \\
\hline Escolha do treinador & 5 \\
\hline Comércio relativo ao time & 7 \\
\hline Interesse do governo no turismo esportivo & 7 \\
\hline
\end{tabular}

Tabela 3 - Elementos influenciadores no futebol brasileiro

A atividade revelou uma matemática importante para a vida cívica dos alunos. A este respeito, Gerardo (2008) mostra alguns pontos a serem vencidos pelos professores na intencionalidade de o alunado aprender a ler o mundo com a matemática: adquirir novas competências no âmbito social, político e econômico; construir nova identidade profissional de educador e, não apenas, de professor de uma disciplina; uma prática profissional mais engajada; se relacionar com o contexto social vivido 
pelos alunos; e, não se prender tanto a um currículo fechado, que visa apenas a preparação para exames nacionais impostos por órgãos público.

$\mathrm{O}$ ambiente provisoriamente construído com a atividade aponta para a possibilidade futura de se tornar real, na instituição da atividade relatada, um cenário para investigação, onde os alunos sejam constantemente sujeitos ativos em sua formação científica e tecnológica. Ao almejar isso, o objetivo mais amplo do ensino da matemática passa a ser a Literacia Crítica cujos focos são: entender a matemática, entender a matemática do conhecimento político, entender a política do conhecimento matemático e entender a política do conhecimento (FRANKENSTEIN, 2006).

\section{Reflexão Final}

Concluo este relato apontando algumas considerações emergidas durante o desenrolar da atividade proposta:

(a) Um cenário mais aberto no ensino de matemática é possível, mesmo quando o currículo é administrado de forma mais fechada pelas políticas públicas e pelas instituições educacionais.

(b) Para contornar o currículo tradicional, que ainda predomina, o professor pode começar realizando pequenos enxertos de atividades, como a relatada neste texto.

(c) A matemática contextualizada se mostra como os demais conhecimentos, filiados às atitudes e aos valores humanos e situados nas realidades sociais, culturais e políticas.

(d) O trabalho de coleta, organização e análise de dados revelou a possibilidade de uma formação mais reflexiva. E gerou uma motivação nos alunos, pois eles se sentiram mais protagonistas em sua formação.

(e) A atividade foi um início de mudança na minha cultura docente, pois me deu ânimo para buscar a construção de um cenário para investigação nas aulas de matemática por mim lecionadas.

\section{Referências}

ALRØ, H.; SKOVSMOSE, O. Diálogo e aprendizagem em educação matemática. Tradução de Orlando Figueiredo. Belo Horizonte: Autêntica, 2006.

DEMO, P. Educação e alfabetização científica. Campinas: Papirus, 2010. 
FRANKENSTEIN, M. Reading the world with math. In: Gutstein, E.; Peterson, B. Rethinking mathematics: teaching social justice by the numbers. Wisconsin: Rethinking Schools, LTD, 2006.

GERARDO, H. Ler o mundo com a Matemática: a intencionalidade em acção. In: Anais... ProfMat2008. Associação de Professores de Matemática (Portugal).

SKOVSMOSE, O. Desafios da reflexão em educação matemática crítica. Campinas: Papirus, 2008.

Submetido em julho de 2012 Aprovado em outubro de 2012 